\title{
Favorable anatomic and visual outcomes with 25-gauge vitrectomy for myopic foveoschisis
}

\author{
This article was published in the following Dove Press journal: \\ Clinical Ophthalmology \\ 12 September 2014 \\ Number of times this article has been viewed
}

Mei Mii

Masato Matsuoka

Kayako Matsuyama

Yayoi Otsu

Tetsuya Nishimura

Department of Ophthalmology, Kansai Medical University, Takii Hospital, Osaka, Japan
Correspondence: Masato Matsuoka Department of Ophthalmology, Kansai Medical University, 10-15 Fumizono-cho, Moriguchi, Osaka 570-8507, Japan $\mathrm{Tel}+8 \mid 66992$ I00I, ext 3322

Fax +81669928263

Email matsuokm@takii.kmu.ac.jp
Purpose: To report the surgical outcomes of 25-gauge vitrectomy in eyes with myopic foveoschisis (MF).

Methods: The medical records of 40 eyes of 36 patients that had undergone 25-gauge vitrectomy with internal limiting membrane peeling for MF were studied. The main outcome measures were the best-corrected visual acuity (BCVA) and the optical coherence tomography (OCT) findings. The eyes were divided into two groups: 1) those with a foveal detachment (FD; FD group); and 2) those without a FD (no-FD group).

Results: The postoperative OCT images showed a resolution of the MF with a significant reduction in the central foveal thickness from the preoperative values in both the FD group ( $479 \pm 150 \mu \mathrm{m}$ to $196 \pm 56 \mu \mathrm{m} ; P=0.002$, mean \pm standard deviation) and in the no-FD group $(369 \pm 116 \mu \mathrm{m}$ to $245 \pm 50 \mu \mathrm{m} ; P=0.001)$. The final mean BCVA significantly improved from the preoperative values in the FD group $(0.96 \pm 0.53$ logarithm of the minimum angle of resolution [logMAR] units to $0.70 \pm 0.56 \log$ MAR units; $P=0.009)$ and in the no-FD group $(0.46 \pm 0.38$ $\log$ MAR units to $0.34 \pm 0.36 \log$ MAR units; $P=0.007)$. The final BCVA in the FD group improved in $63 \%$, remained unchanged in $31 \%$, and worsened in $6 \%$. In the no-FD group, the final BCVA improved in $21 \%$, remained unchanged in $71 \%$, and worsened in $8 \%$ of the eyes. A better final BCVA was significantly correlated with a better preoperative BCVA in both groups $(P<0.001)$

Conclusion: Twenty five-gauge vitrectomy results in favorable visual and anatomic outcomes for MF. We recommend that 25-gauge vitrectomy be used to treat eyes with MF.

Keywords: myopic foveoschisis, 25-gauge vitrectomy, high myopia, internal limiting membrane, gas tamponade

\section{Introduction}

Myopic foveoschisis (MF) is one of the major causes of vision reduction in myopic patients, and its presence has been increasingly recognized with the advent of optical coherence tomography (OCT). ${ }^{1,2}$ The estimated incidence of MF ranges from $8 \%-34 \%$ in eyes with high myopia. ${ }^{3-7}$ Because MF is typically a slowly progressive condition, the majority of the patients retain relatively good vision. ${ }^{8}$ However, progression to more serious complications, such as foveal detachments (FD), epiretinal membrane (ERM), full-thickness macular hole (MH), and macular hole retinal detachment (MHRD), can occur during its natural course. ${ }^{9-11}$ Thus, surgical intervention is needed in these patients to prevent anatomic and functional worsening of the retina and vision. ${ }^{12,13}$

Minimally invasive vitreous surgery with 23- and 25-gauge instruments has been developed. The advantages of minimally invasive vitreous surgery are that no wound suture is required because of the smaller incision size, less inflammation, less patient 

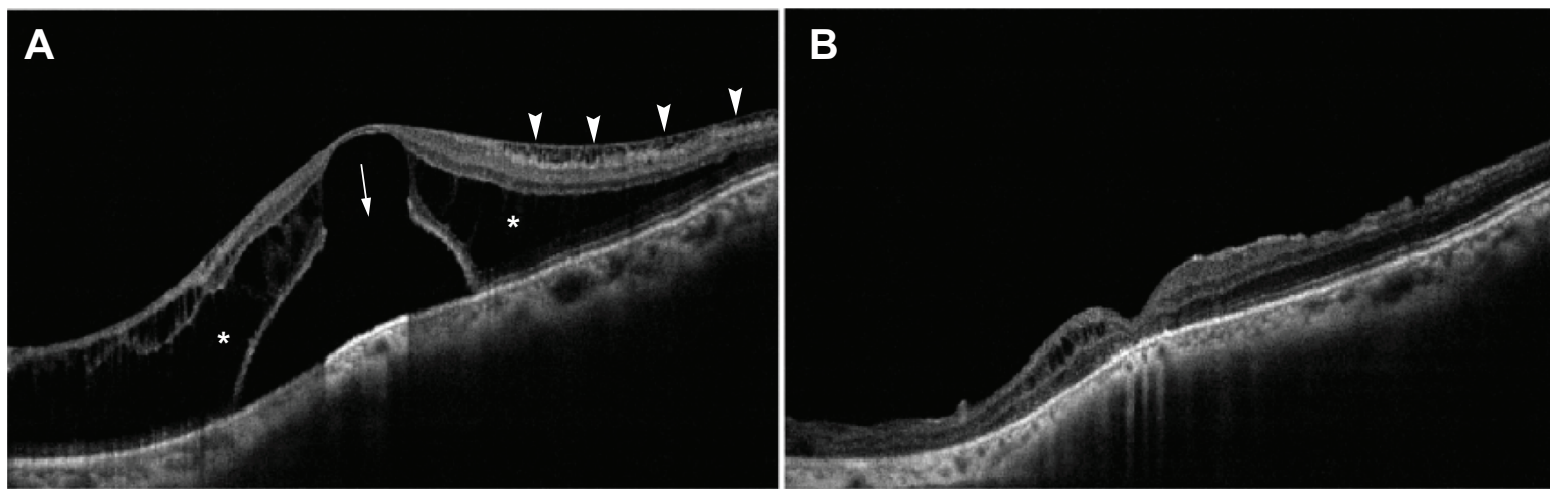

Figure I OCT images of an eye with myopic foveoschisis with FD group.

Notes: (A) Preoperative OCT image shows outer retinoschisis (asterisks), inner retinoschisis (arrowheads), and foveal detachment with outer lamellar hole (arrow). (B) OCT image at 16 months after vitrectomy with internal limiting membrane (ILM) peeling shows a resolution of the foveoschisis and reattachment of the fovea. Abbreviations: OCT, optical coherence tomographic; FD, foveal detachment.

discomfort, faster recovery of visual acuity, and occasional shorter operative time. ${ }^{14}$ Therefore, the indications for 25 -gauge vitrectomy have been expanded..$^{15-17}$

Many studies have already demonstrated the effectiveness of 20-gauge vitrectomy in treating MF. $\cdot^{12,13,18-23}$ However, little has been reported about the surgical outcome with the 25 -gauge vitrectomy. Thus, the purpose of this study was to report the surgical outcomes of 25 -gauge vitrectomy in eyes of MF.

\section{Materials and methods Subjects}

The procedures used in this study conformed to the tenets of the World Medical Association's Declaration of Helsinki. This was a retrospective study of 40 eyes in 36 consecutive patients who underwent the 25-gauge vitrectomy for MF at the Kansai Medical University Takii Hospital (Osaka, Japan) between January 2007 and April 2013. All of the patients had

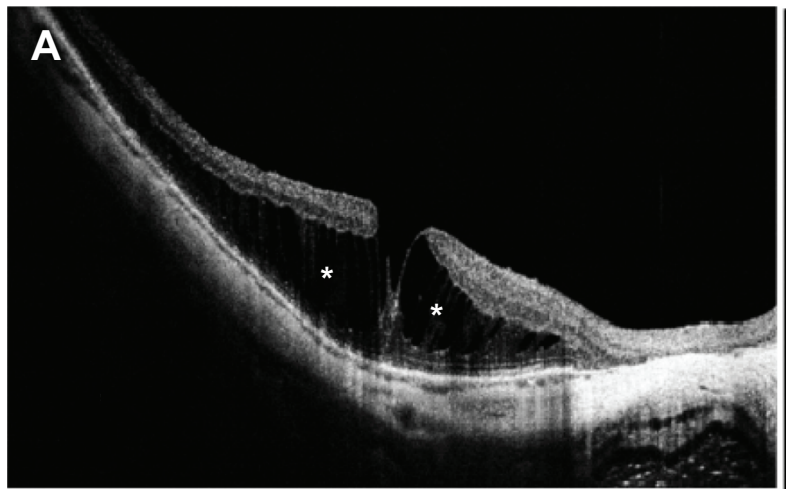

a progressive reduction of their vision or metamorphopsia that was attributable to MF. The exclusion criteria included eyes with other retinal disease that could affect the central vision, eg, full-thickness MH, MHRD, choroidal neovascularization, macular atrophy, axial length $<26.0 \mathrm{~mm}$, or follow-up $<6$ months. The eyes were divided into two groups based on the foveal anatomy in the OCT images - those with a FD (FD group; Figure 1) and those without a FD (no-FD group; Figure 2).

\section{Data collection}

All patients had a complete ophthalmic examination, including measurement of the best-corrected visual acuity (BCVA), refraction, slit-lamp examination, fundus examination, color fundus photography, and OCT. The preoperative and postoperative BCVAs were determined as decimal visual acuity and then converted to logarithm of the minimum angle of resolution (logMAR) units for statistical

Figure 2 OCT images of an eye with myopic foveoschisis no-FD group.

Notes: (A) Preoperative OCT image shows outer retinoschisis (asterisks). (B) OCT image at 5 months after vitrectomy with ILM peeling shows a resolution of foveoschisis.

Abbreviations: OCT, optical coherence tomographic; ILM, internal limiting membrane; no-FD, no foveal detachment.

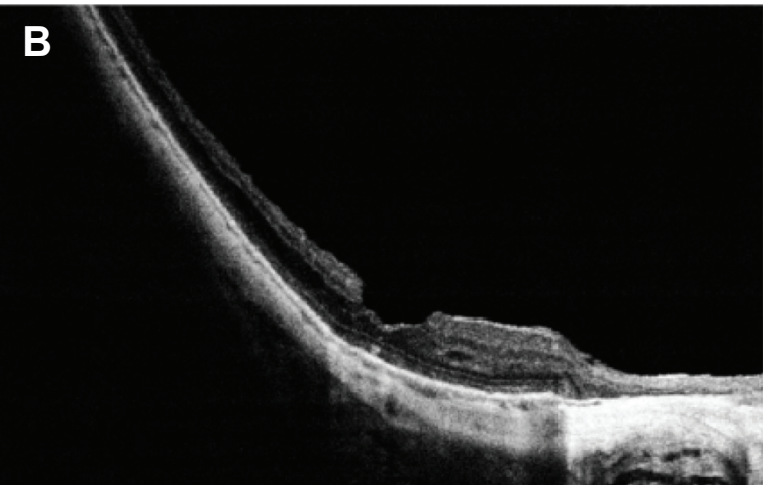


analyses. An improvement or worsening of the postoperative BCVA was defined as a change $>0.2 \log$ MAR units. The preoperative and postoperative OCT recordings were performed with the OCT 3 (Carl Zeiss Meditec AG, Jena, Germany) or RTVue-100 (Optovue Inc., Fremont, CA, USA).

\section{Surgical procedures}

All surgeries were performed by one experienced surgeon (TN). The patients underwent the standard three-port 25 -gauge pars plana vitrectomy with the insertion of a beveled cannula under retrobulbar anesthesia. Phacoemulsification with implantation of an intraocular lens was performed to avoid the effects of postoperative cataract development in 25 of the phakic eyes. The internal limiting membrane (ILM) was stained with $0.1 \%$ indocyanine green (ICG) or triamcinolone acetonide, and peeled over two to three disc diameters by intraocular forceps in all eyes. The decision to use gas tamponade was made based on the surgeon's discretion, ie, the cases in which the macular hole or retinal breaks had occurred. A gas tamponade was made by injecting $20 \%$ sulfur hexafluoride in four eyes or air in five eyes after the fluid-air exchange. The patients with gas tamponade were encouraged to maintain a prone posture for at least a week postoperatively. When a leakage was detected at sclerotomy, the wound was sutured by 9-0 VICRYL ${ }^{\circledR}$ (Johnson \& Johnson, New Brunswick, NJ, USA).

\section{Statistical analyses}

The results are expressed as the means \pm standard deviations. The data were analyzed with Mann-Whitney $U$-tests, Wilcoxon paired signed-rank tests, Kruskal-Wallis test, and analysis of covariance. Associations between the final BCVA and the clinical parameters were examined by Pearson product moment correlation coefficients and multiple linear regression analyses. Differences were considered significant when the $P$-value was $<0.05$. All statistical analyses of the data were performed with IBM ${ }^{\circledR}$ SPSS $^{\circledR}$ Statistics for Windows (version 22; IBM Corporation, Armonk, NY, USA).

\section{Results}

\section{Preoperative characteristics}

Forty eyes of 36 consecutive patients underwent 25-gauge vitrectomy; five were men and 31 were women. Their ages at the time of surgery ranged from 50-84 years with a mean of 70.0 \pm 7.7 years (Table 1). Of the 40 eyes, 25 were phakic, 14 were pseudophakic, and one was aphakic. The mean axial length was $28.9 \mathrm{~mm}$, with a range from $26.2-32.8 \mathrm{~mm}$. The mean postoperative follow-up period was $32.0 \pm 23.3$ months with a range from 6-84 months.

Preoperatively, a foveoschisis was detected in all eyes by OCT. There were 16 eyes with FD (FD group) and 24 eyes without a FD (no-FD group). The preoperative differences in age, axial length, and postoperative follow-up periods were not significant between the two groups (Table 1). In contrast, the preoperative central foveal thickness and BCVA between two groups were significantly different $(P=0.019$ and $P=0.003$, respectively; Table 2 ).

\section{Surgical outcomes}

Postoperative OCT showed a resolution of MF and a reattachment of the fovea in all eyes during the follow-up period (Figures 1 and 2). The postoperative central foveal thickness was significantly reduced from the preoperative values in FD group (479 $\pm 150 \mu \mathrm{m}$ to $196 \pm 56 \mu \mathrm{m} ; P=0.002$; Table 2 ) and

Table I Clinical characteristic of patients

\begin{tabular}{llll}
\hline Category & FD group $(\mathbf{n}=\mathbf{l 6})$ & No-FD group $(\mathbf{n}=\mathbf{2 4})$ & P-value* \\
\hline Age range (years) & $60-83$ & $50-84$ & NA \\
Mean \pm SD & $70.9 \pm 6.6$ & $69.3 \pm 8.5$ & 0.62 \\
Sex (male/female) & $2 / 14$ & $3 / 21$ & NA \\
Lens status (n) & 12 & 13 & NA \\
Phakic & 0 & 1 & NA \\
Aphakic & 4 & 10 & NA \\
IOL & & & NA \\
Axial length (mm) & $26.2-32.8$ & $26.4-31.4$ & 0.41 \\
Range & $28.7 \pm 2.2$ & $29.21 \pm 1.4$ & NA \\
Mean \pm SD & & & 0.58 \\
Postoperative follow-up (months) & $6-84$ & $6-78$ & $30.8 \pm 23.0$ \\
Range & $34.2 \pm 24.5$ & \\
Mean \pm SD & & \\
\hline
\end{tabular}

Notes: *P-value between FD group and no-FD group (Mann-Whitney U-test).

Abbreviations: FD, foveal detachment; no-FD, without foveal detachment; SD, standard deviation; NA, not available; IOL, intraocular lens. 
Table 2 Anatomic and visual outcomes

\begin{tabular}{|c|c|c|c|}
\hline Category & $\begin{array}{l}\text { FD group } \\
(n=16)\end{array}$ & $\begin{array}{l}\text { No-FD group } \\
(n=24)\end{array}$ & $P$-value \\
\hline \multicolumn{4}{|c|}{ Central foveal thickness $(\mu \mathrm{m})$} \\
\hline Preoperative & $479 \pm 150$ & $369 \pm 116$ & $0.019 *$ \\
\hline Postoperative & $196 \pm 56$ & $245 \pm 50$ & $0.037^{*}$ \\
\hline$P$-value & $0.002^{\dagger}$ & $0.00 \mathrm{It}^{\dagger}$ & NA \\
\hline \multicolumn{4}{|l|}{ BCVA (logMAR) } \\
\hline Preoperative & $0.96 \pm 0.53$ & $0.46 \pm 0.38$ & $0.003 *$ \\
\hline Postoperative (final) & $0.70 \pm 0.56$ & $0.34 \pm 0.36$ & $0.045^{*}$ \\
\hline$P$-value & $0.009^{\dagger}$ & $0.007^{\dagger}$ & NA \\
\hline \multicolumn{4}{|l|}{ Change in BCVA ${ }^{\ddagger}, \mathrm{n}(\%)$} \\
\hline Improve & $10(63)$ & $5(2 I)$ & $0.017^{\S}$ \\
\hline Unchanged & $5(3 I)$ & $17(7 \mid)$ & NA \\
\hline Worsened & I (6) & $2(8)$ & NA \\
\hline \multicolumn{4}{|c|}{ Postoperative complication, n (\%) } \\
\hline Full-thickness macular hole & $\mathrm{I}(6.3)$ & $2(8.3)$ & NA \\
\hline Retinal detachment & $2(12.5)$ & $0(0)$ & NA \\
\hline Transient hypotony & $0(0)$ & $4(16.7)$ & NA \\
\hline Transient CD & $0(0)$ & I (4.I) & NA \\
\hline
\end{tabular}

Notes: ${ }^{* P}$-value between FD group and no-FD group (Mann-Whitney $U$-test). ${ }^{\dagger} P$-value between preoperative and postoperative values (Wilcoxon paired signed-rank test). ${ }^{\ddagger}$ An improvement or worsening of visual acuity was defined as a change $>0.2$ logMAR units. ${ }^{\$}$-value between preoperative and postoperative values (Kruskal-Wallis test). Hypotony, mean intraocular pressure $<6 \mathrm{mmHg}$.

Abbreviations: FD, foveal detachment; no-FD, no foveal detachment; BCVA, best-corrected visual acuity; NA, not available; CD, choroidal detachment.

in the no-FD group $(369 \pm 116 \mu \mathrm{m}$ to $245 \pm 50 \mu \mathrm{m} ; P=0.001$; Table 2).

The final BCVA significantly improved from the preoperative values in the FD group $(0.96 \pm 0.53 \log$ MAR to $0.70 \pm 0.56 \log$ MAR; $P=0.009$; Table 2$)$ and in the no-FD group (0.46 $\pm 0.38 \log$ MAR to $0.34 \pm 0.36 \log$ MAR; $P=0.007$; Table 2). The percentage of eyes with a significant improvement of the final BCVA in FD group was greater than that in no-FD group ( $P=0.017$; Table 2$)$. The final BCVA in the FD group improved in $63 \%$, remained unchanged in $31 \%$, and worsened in $6 \%$. In the no-FD group, the final BCVA improved in $21 \%$, remained unchanged in $71 \%$, and worsened in $8 \%$ of the eyes. The final BCVA was significantly correlated with the preoperative BCVA in the FD group $\left(r^{2}=0.74 ; P<0.001\right.$; Figure $3 \mathrm{~A})$ and in the no-FD group $\left(r^{2}=0.62 ; P<0.001\right.$; Figure 3B). The improvement of BCVA was not correlated with the presence of a FD, concomitant phacoemulsification, gas tamponade, and method of ILM visualization ( $P=0.71$, $0.16,0.63$, and 0.88 , respectively; Table 3 ).

Multiple linear regression analyses showed that the final BCVA was significantly correlated with preoperative BCVA (adjusted $R^{2}=0.66 ; P<0.001$; Table 4 ), but not with age $(P=0.49)$, axial length $(P=0.08)$, preoperative central foveal thickness $(P=0.61), \mathrm{FD}(P=0.84)$, concomitant
A

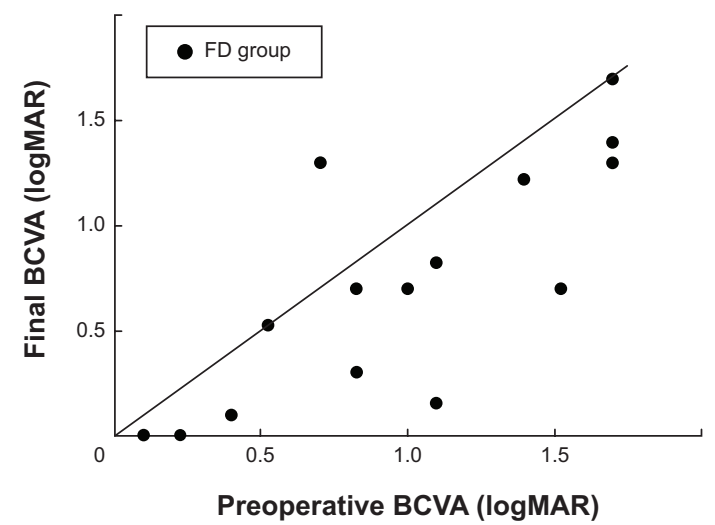

B

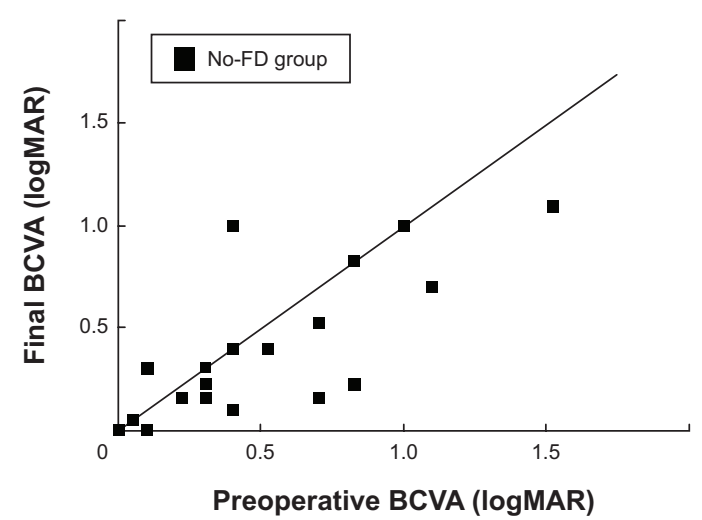

Figure 3 Relationship between preoperative and final BCVA in patients with myopic foveoschisis.

Notes: (A) Preoperative and final BCVA are significantly correlated in eyes with foveal detachment (FD group; $n=16 ; r^{2}=0.74 ; P<0.001$ ). (B) Preoperative and final BCVA are significantly correlated in eyes without foveal detachment (no-FD group; $n=24 ; r^{2}=0.62 ; P<0.00 I$ ). Pearson's product moment correlation coefficients.

Abbreviations: BCVA, best-corrected visual acuity; FD, foveal detachment; logMAR, logarithm of the minimal angle of resolution. 
Table 3 Visual acuity improvement after 25-gauge vitrectomy

\begin{tabular}{|c|c|c|c|c|}
\hline Category & $\mathbf{N}$ & $\begin{array}{l}\text { Preoperative BCVA } \\
\text { (logMAR) }\end{array}$ & $\begin{array}{l}\text { Final BCVA } \\
\text { (logMAR) }\end{array}$ & $P$-value* \\
\hline \multicolumn{5}{|c|}{ Foveal detachment } \\
\hline Positive & 16 & $0.96 \pm 0.53$ & $0.70 \pm 0.56$ & NA \\
\hline Negative & 24 & $0.46 \pm 0.38$ & $0.34 \pm 0.36$ & 0.71 \\
\hline \multicolumn{5}{|c|}{ Phacoemulsification } \\
\hline Concomitant & 25 & $0.69 \pm 0.56$ & $0.46 \pm 0.52$ & NA \\
\hline None & 15 & $0.60 \pm 0.42$ & $0.52 \pm 0.4 \mathrm{I}$ & 0.16 \\
\hline \multicolumn{5}{|c|}{ Gas tamponade } \\
\hline Concomitant & 9 & $0.90 \pm 0.68$ & $0.63 \pm 0.53$ & NA \\
\hline None & 31 & $0.59 \pm 0.44$ & $0.44 \pm 0.46$ & 0.63 \\
\hline \multicolumn{5}{|c|}{ Visualization of ILM } \\
\hline ICG-use & 22 & $0.66 \pm 0.57$ & $0.48 \pm 0.53$ & NA \\
\hline TA-use & 18 & $0.65 \pm 0.43$ & $0.49 \pm 0.42$ & 0.88 \\
\hline
\end{tabular}

Notes: $* P$-value from the differences between positive and negative in foveal detachment category, concomitant, and none in the phacoemulsification category and in the gas tamponade category, and ICG-use and TA-use in visualization of ILM category (respectively; analysis of covariance).

Abbreviations: BCVA, best-corrected visual acuity; NA, not available; logMAR, logarithm of the minimal angle of resolution; ILM, internal limiting membrane; ICG, indocyanine green; TA, triamcinolone acetonide.

phacoemulsification $(P=0.35)$, gas tamponade $(P=0.48)$, or with use of ICG or triamcinolone acetonide $(P=0.83)$.

\section{Surgical complications}

The postoperative complications in the FD group (16 eyes) included one with a MH (6.3\%; Table 2) and two with a retinal detachment from a peripheral retinal break $(12.5 \%)$. In the no-FD group (24 eyes), two eyes developed a $\mathrm{MH}$ (8.3\%), four had hypotony (intraocular pressure $<6 \mathrm{mmHg}$; $16.7 \%)$, and one had a choroidal detachment (4.1\%). In the eyes with a postoperative $\mathrm{MH}$, the preoperative inner segment/outer segment (IS/OS) junction line was disrupted or irregular at the fovea in the OCT images. These eyes underwent reoperation, and the $\mathrm{MH}$ was closed in one eye (FD group), but not in the other eye (no-FD group). The hypotony and choroidal detachment recovered without additional treatments within a week after the operation. The two eyes with a retinal detachment underwent reoperation, and the retinas were reattached.

\section{Discussion}

Our results confirmed the results of earlier studies that showed that 25-gauge vitrectomy with ILM peeling results in good anatomic and BCVA in eyes with MF. Evidence of these findings is based on the following: postoperative OCT showed a resolution of MF and a reattachment of the fovea in all eyes (Table 2; Figures 1 and 2), final mean BCVA significantly improved (Table 2), and better final BCVA was correlated with better preoperative BCVA (Table 4; Figure 3).

Vitrectomy or episcleral macular buckling has generally been used to treat MF. ${ }^{2}$ Although many studies had reported on the efficacy of episcleral macular buckling, this surgery has the potential complications, eg, difficult intraoperative access to posterior pole and risk of scleral perforation. ${ }^{2}$ Vitrectomy was believed to be a rational choice for the treatment of MF, because a MF was believed to be caused by premacular vitreous traction with a rigidity of the ILM and ERM, stiffness of the retinal vessels, and posterior staphyloma. Thus, vitrectomy with ILM peeling was expected to remove the tractional tension. ${ }^{7,18,20,24-26}$

Earlier studies reported on the favorable outcomes of 20-gauge vitrectomy for MF. ${ }^{12,13,18-23}$ More recently, Shimada et al reported on the surgical outcomes of 25-gauge vitrectomy for MF with FD, but they did not report on eyes without a FD. ${ }^{27}$ Shin et al reported on the outcomes of 25 -gauge vitrectomy, but they did not compare the results in a FD group to a no-FD group. ${ }^{28} \mathrm{We}$ now report on the surgical outcomes of 25-gauge vitrectomy for MF with and without FD.

Table 4 Multiple linear regression analysis for final visual acuity

\begin{tabular}{lll}
\hline Independent variable & $\beta^{*}$ & $P$-value \\
\hline Age & 0.07 & 0.49 \\
Axial length & -0.19 & 0.08 \\
Preoperative BCVA & 0.81 & $<0.00$ I \\
Preoperative central foveal thickness & -0.06 & 0.61 \\
Foveal detachment & 0.03 & 0.84 \\
Concomitant phacoemulsification & 0.10 & 0.35 \\
Gas tamponade & 0.08 & 0.48 \\
Visualization of ILM & $\mathrm{NA}$ & $\mathrm{NA}$ \\
ICG-use or TA-use & -0.02 & 0.83
\end{tabular}

Notes: Adjusted $R^{2}=0.66$ for final BCVA in multiple linear regression analysis $(P<0.00 \mathrm{I})$. *Standard partial regression coefficient.

Abbreviations: NA, not available; BCVA, best-corrected visual acuity; ILM, internal limiting membrane; ICG, indocyanine green; TA, triamcinolone acetonide. 
Our results contain six major findings. First, 25-gauge vitrectomy resulted in favorable visual outcomes for MF; whereas, the visual improvement percentage in the no-FD group was lower than that in the FD group (21\% versus 63\%; Table 2). Earlier studies reported that the postoperative BCVA in patients in the FD group recovered, and the incidence was high, as did our results. ${ }^{12,13,22,27,29}$ This is quite reasonable because a reattachment of photoreceptors at the fovea should lead to recovery of the BCVA. Thus, eyes with FD are good candidates for vitrectomy. ${ }^{12}$ In contrast, several investigators reported that the final BCVA did not improve significantly in no-FD eyes. ${ }^{12,13}$ These other studies ${ }^{22,29}$ and our results showed a significant improvement of the final BCVA in the no-FD group, although the incidence of eyes with a visual improvement was low. This indicates that foveoschisis without a FD can result in decreased BCVA, which can be resolved by vitreous surgery. ${ }^{12}$ Additionally, FD, MH, or MHRD can develop in the no-FD group during its natural course. ${ }^{9-11}$ Thus, vitrectomy can prevent these changes and, thus, should be a useful treatment for the no-FD group to prevent further disease progression and retinal function damage.

Second, the final BCVA was significantly correlated with the preoperative BCVA in both the FD group and no-FD group (Table 4; Figure 3). These results agree with earlier reports on $\mathrm{MF}^{12,13,28}$ and also other macular disorders, such as ERM. ${ }^{30}$ This suggests that patients with MF should undergo surgery as soon as possible. However, to establish the surgical indications for MF is difficult because patients without a FD retain relatively good vision and do not visit eye doctors. ${ }^{8}$ Thus, patients who have progressive visual impairments, ie, vision reduction and metamorphopsia or FD attributable to MF should be good candidates for vitrectomy with ILM peeling.

Third, MF can be resolved by 25 -gauge vitrectomy with ILM peeling in all eyes (Table 2; Figures 1 and 2). To date, the evidence that supports the need for ILM peeling is inconsistent. Many studies reported that vitrectomy with ILM peeling resulted in better anatomic and visual outcomes. ${ }^{12,13,18,19,27,31}$ On the other hand, other investigators reported on the effectiveness of vitrectomy without ILM peeling. ${ }^{20-22,32,33}$ Although ILM peeling can be a risk factor for iatrogenic $\mathrm{MH}$ in highly myopic eyes with very thin retina, ${ }^{20,27}$ it may ensure a complete removal of all premacular vitreous traction and decrease the retinal rigidity to conform better to the posterior staphyloma. ${ }^{24,26,34}$ In addition, Taniuchi et al reported that a recurrence of tractional macular detachment was observed more frequently in the eye without ILM peelings. ${ }^{29}$ Thus, we believe that ILM peeling is essential for resolving a $\mathrm{MF}$.
Fourth, 25-gauge vitrectomy resulted in favorable anatomic and visual outcomes for MF with or without a gas tamponade (Table 2). The evidence to support the need for a gas tamponade also remains inconsistent. The rationale for a gas tamponade to treat a MF is because the gas is expected to push the retina back and close any paravascular breaks, which occasionally occur in highly myopic eyes. ${ }^{12,18-21,27,33}$ However, several studies have shown that vitrectomy without a gas tamponade also resulted in good anatomic and visual

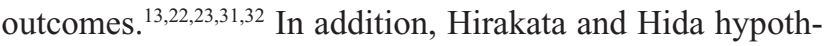
esized that gas tamponade could be a cause of $\mathrm{MH}$-formation because intraocular gas might push the subretinal fluid into the limited space under the FD toward the thin foveola. ${ }^{22}$ Thus, vitrectomy without gas tamponade might be a good treatment of $\mathrm{MF}$ - except for the cases in which intraoperative $\mathrm{MH}$ or retinal breaks had occurred. In support of this, we found that the final BCVA was not significantly correlated with whether a gas tamponade was used (Tables 3 and 4).

Fifth, a full-thickness $\mathrm{MH}$ can develop postoperatively as it did in three of 40 eyes (7.5\%; Table 2$)$. A postoperative $\mathrm{MH}$ is a serious complication in eyes with MF and the surgical results of this are not good. ${ }^{18,22}$ Gao et al reported that a defect in the IS/OS junction could be a risk factor for postoperative $\mathrm{MH}$ in the treatment of $\mathrm{MF} .{ }^{35}$ Of the three eyes with a postoperative $\mathrm{MH}$, two had an IS/OS junction defect (FD group and no-FD group), and one had an irregular IS/ OS junction (no-FD group). Therefore, ILM peelings should be performed with care in eyes with $\mathrm{MF}$ and a defect in the IS/OS junction. ${ }^{35}$

Sixth, we found that the postoperative complications included transient hypotony $(10.0 \%)$ and choroidal detachment (2.5\%; Table 2). The 25-gauge sutureless vitrectomy technique is known to have higher incidence of postoperative wound leaks, hypotony, and endophthalmitis. ${ }^{36}$ Thus, using a beveled cannula has been recommended to prevent these complications. ${ }^{37,38}$ In highly myopic eyes, however, to create a self-sealing incision is occasionally difficult because the sclera is thin and of low rigidity, even if a beveled cannula is used. ${ }^{39}$ Although hypotony and choroidal detachment usually recover without additional treatment, ${ }^{15}$ a careful check of wound leakage is essential intraoperatively because wound leakage can be a cause of serious complications, such as endophthalmitis.

Our study has some limitations. This was a retrospective and nonrandomized study with a small number of cases and a short follow-up period. Therefore, further prospective and randomized clinical trials are needed with larger sample sizes. 
In conclusion, our results show that 25-gauge vitrectomy with ILM peeling results in favolable anatomic and visual outcomes for eyes with myopic foveoschisis. In addition, our results show that the preoperative BCVA is a good predictor of the final BCVA. These results indicate that 25 -gauge vitrectomy is a rational treatment for the patients who have progressive visual impairments due to myopic foveoschisis.

\section{Disclosure}

The authors report no conflicts of interest in this work.

\section{References}

1. Tano Y. Pathologic myopia: where are we now? Am J Ophthalmol. 2002;134(5):645-660.

2. Todorich B, Scott IU, Flynn HW Jr, Chang S. Macular retinoschisis associated with pathologic myopia. Retina. 2013;33(4):678-683.

3. Takano M, Kishi S. Foveal retinoschisis and retinal detachment in severely myopic eyes with posterior staphyloma. Am J Ophthalmol. 1999; 128(4):472-476.

4. Benhamou N, Massin P, Haouchine B, Erginay A, Gaudric A. Macular retinoschisis in highly myopic eyes. Am J Ophthalmol. 2002; 133(6):794-800.

5. Baba T, Ohno-Matsui K, Futagami S, et al. Prevalence and characteristics of foveal retinal detachment without macular hole in high myopia. Am J Ophthalmol. 2003;135(3):338-342.

6. Panozzo G, Mercanti A. Optical coherence tomography findings in myopic traction maculopathy. Arch Ophthalmol. 2004;122(10): $1455-1460$.

7. Wu PC, Chen YJ, Chen YH, et al. Factors associated with foveoschisis and foveal detachment without macular hole in high myopia. Eye (Lond). 2009;23(2):356-361.

8. Ichibe M, Baba E, Funaki S, Yoshizawa T, Abe H. Retinoschisis in a highly myopic eye without vision impairment. Retina. 2004; 24(2):331-333.

9. Shimada N, Ohno-Matsui K, Baba T, Futagami S, Tokoro T, Mochizuki M. Natural course of macular retinoschisis in highly myopic eyes without macular hole or retinal detachment. Am J Ophthalmol. 2006;142(3):497-500.

10. Gaucher D, Haouchine B, Tadayoni R, et al. Long-term follow-up of high myopic foveoschisis: natural course and surgical outcome. Am J Ophthalmol. 2007;143(3):455-462.

11. Shimada N, Ohno-Matsui K, Yoshida T, Sugamoto Y, Tokoro T, Mochizuki M. Progression from macular retinoschisis to retinal detachment in highly myopic eyes is associated with outer lamellar hole formation. Br J Ophthalmol. 2008;92(6):762-764.

12. Ikuno Y, Sayanagi K, Soga K, Oshima Y, Ohji M, Tano Y. Foveal anatomical status and surgical results in vitrectomy for myopic foveoschisis. Jpn J Ophthalmol. 2008;52(4):269-276.

13. Kumagai K, Furukawa M, Ogino N, Larson E. Factors correlated with postoperative visual acuity after vitrectomy and internal limiting membrane peeling for myopic foveoschisis. Retina. 2010;30(6):874-880.

14. Fujii GY, De Juan E Jr, Humayun MS, et al. A new 25-gauge instrument system for transconjunctival sutureless vitrectomy surgery. Ophthalmology. 2002;109(10):1807-1812; discussion 1813.

15. Shimada H, Nakashizuka H, Mori R, Mizutani Y. Expanded indications for 25-gauge transconjunctival vitrectomy. Jpn J Ophthalmol. 2005;49(5):397-401.

16. Recchia FM, Scott IU, Brown GC, Brown MM, Ho AC, Ip MS. Smallgauge pars plana vitrectomy: a report by the American Academy of Ophthalmology. Ophthalmology. 2010;117(9):1851-1857.
17. Thompson JT. Advantages and limitations of small gauge vitrectomy. Surv Ophthalmol. 2011;56:162-172.

18. Kobayashi H, Kishi S. Vitreous surgery for highly myopic eyes with foveal detachment and retinoschisis. Ophthalmology. 2003;110(9): 1702-1707.

19. Kanda S, Uemura A, Sakamoto Y, Kita H. Vitrectomy with internal limiting membrane peeling for macular retinoschisis and retinal detachment without macular hole in highly myopic eyes. Am J Ophthalmol. 2003;136(1):177-180.

20. Spaide RF, Fisher Y. Removal of adherent cortical vitreous plaques without removing the internal limiting membrane in the repair of macular detachments in highly myopic eyes. Retina. 2005;25(3):290-295.

21. Kwok AK, Lai TY, Yip WW. Vitrectomy and gas tamponade without internal limiting membrane peeling for myopic foveoschisis. $\mathrm{Br} \mathrm{J}$ Ophthalmol. 2005;89(9):1180-1183.

22. Hirakata A, Hida T. Vitrectomy for myopic posterior retinoschisis or foveal detachment. Jpn J Ophthalmol. 2006;50(1):53-61.

23. Panozzo G, Mercanti A. Vitrectomy for myopic traction maculopathy. Arch Ophthalmol. 2007;125(6):767-772.

24. Kuhn F. Internal limiting membrane removal for macular detachment in highly myopic eyes. Am J Ophthalmol. 2003;135(4):547-549.

25. Ikuno Y, Gomi F, Tano Y. Potent retinal arteriolar traction as a possible cause of myopic foveoschisis. Am J Ophthalmol. 2005;139(3):462-467.

26. Sayanagi K, Ikuno Y, Tano Y. Tractional internal limiting membrane detachment in highly myopic eyes. Am J Ophthalmol. 2006; 142(5):850-852.

27. Shimada N, Sugamoto Y, Ogawa M, Takase H, Ohno-Matsui K. Fovea-sparing internal limiting membrane peeling for myopic traction maculopathy. Am J Ophthalmol. 2012;154(4):693-701.

28. Shin JY, Yu HG. Visual prognosis and spectral-domain optical coherence tomography findings of myopic foveoschisis surgery using 25-gauge transconjunctival sutureless vitrectomy. Retina. 2012;32(3):486-492.

29. Taniuchi S, Hirakata A, Itoh Y, Hirota K, Inoue M. Vitrectomy with or without internal limiting membrane peeling for each stage of myopic traction maculopathy. Retina. 2013;33(10):2018-2025.

30. Kumagai K, Ogino N. Results of epiretinal membrane removal combined with PEA and IOL. Semin Ophthalmol. 2001;16(3):151-157.

31. Kim KS, Lee SB, Lee WK. Vitrectomy and internal limiting membrane peeling with and without gas tamponade for myopic foveoschisis. $\mathrm{Am}$ J Ophthalmol. 2012;153(2):320-326.e1.

32. Ratiglia R, Osnaghi S, Bindella A, Pirondini C. Posterior traction retinal detachment in highly myopic eyes: clinical features and surgical outcome as evaluated by optical coherence tomography. Retina. 2005;25(4):473-478.

33. Yeh SI, Chang WC, Chen LJ. Vitrectomy without internal limiting membrane peeling for macular retinoschisis and foveal detachment in highly myopic eyes. Acta Ophthalmol. 2008;86(2):219-224.

34. Abdelkader E, Lois N. Internal limiting membrane peeling in vitreoretinal surgery. Surv Ophthalmol. 2008;53(4):368-396.

35. Gao X, Ikuno Y, Fujimoto S, Nishida K. Risk factors for development of full-thickness macular holes after pars plana vitrectomy for myopic foveoschisis. Am J Ophthalmol. 2013;155(6):1021-1027.e1.

36. Govetto A, Virgili G, Menchini F, Lanzetta P, Menchini U. A systematic review of endophthalmitis after microincisional versus 20-gauge vitrectomy. Ophthalmology. 2013;120(11):2286-2291.

37. Inoue M, Shinoda K, Shinoda H, Kawamura R, Suzuki K, Ishida S. Two-step oblique incision during 25-gauge vitrectomy reduces incidence of postoperative hypotony. Clin Experiment Ophthalmol. 2007;35(8):693-696.

38. Kunimoto DY, Kaiser RS; Wills Eye Retina Service. Incidence of endophthalmitis after 20- and 25-gauge vitrectomy. Ophthalmology. 2007;114(12):2133-2137.

39. Ikuno Y, Asai T, Yano S, Nishida K. [Small gauge vitrectomy in macular surgery for myopic complications]. Nihon Ganka Gakkai Zasshi. 2012;116(12):1130-1136. Japanese. 


\section{Publish your work in this journal}

Clinical Ophthalmology is an international, peer-reviewed journal covering all subspecialties within ophthalmology. Key topics include: Optometry; Visual science; Pharmacology and drug therapy in eye diseases; Basic Sciences; Primary and Secondary eye care; Patient Safety and Quality of Care Improvements. This journal is indexed on

Submit your manuscript here: http://www.dovepress.com/clinical-ophthalmology-journal
PubMed Central and CAS, and is the official journal of The Society of Clinical Ophthalmology (SCO). The manuscript management system is completely online and includes a very quick and fair peer-review system, which is all easy to use. Visit http://www.dovepress.com/ testimonials.php to read real quotes from published authors. 